\title{
Empirical Study on National Equities Exchange and Quotations under Market-maker System with VaR method Based on GARCH Model
}

\author{
Xiangguo Jia \\ School of Economics, Shanghai University, Shanghai, China
}

Keywords: market-maker system; GARCH model; VaR method; risk measurement; NEEQ

\begin{abstract}
This paper conducts empirical research and regulations on the risk of National Equities Exchange and Quotations under the market-maker system in China, and outlines the VaR method based on GARCH model after summarizing the domestic and foreign literatures on the risk measurement and control of NEEQ market-maker system, then performs empirical study on risk measurement of the market maker index of NEEQ, and verifing VaR values of the sample data with failure frequency test method based on the calculation of VaR values. The results show that VaR method based on the GARCH model can be effectively applied to the risk management of NEEQ under the market-maker system in China.
\end{abstract}

\section{Introduction}

\subsection{Research Significance}

National Equities Exchange and Quotations (hereinafter referred as NEEQ), as the key to the construction of multi-level equity financing of China, has played an important role in providing highly effective financing channels and equity transfer service for small and medium-sized enterprises and start-ups. Since the introduction of market-maker system to the NEEQ in 2014, with the increasing number of listing enterprises in the NEEQ, the coverage of industries involved has been expanding, the scale of circulating capital stocks has continued to grow, and the NEEQ has drown more attention from investors. With the gradual acceleration of the pace of innovation and reform of China's financial system, China's NEEQ is in full swing and has broad prospects. Combined with special financial status of NEEQ and generalized law of market, this paper constructs VaR estimation model of NEEQ under market-maker system based on GARCH model, and performs risk prediction of entire NEEQ market under market-maker system with this model. In the new era of China's financial system reform and innovation, this paper can provide certain decision-making basis and theoretical reference for financial institutions, regulatory agencies and investors in NEEQ market.

\subsection{Literature Review}

The NEEQ originated from the United States, and foreign scholars have begun to study the system earlier. Richard Roll (1984) considered that in reality, market makers mainly profit from the bid-ask spread, based on theory of Demsetz. According to the hypothetical conditions of the effective market, a measure of the effective bid-ask spread is proposed. Henk Berkman (1996) found that the positive relationship between investment income and liquidity is more conducive to the dissemination of stock transaction information with market-maker system than the limit order trading system, mainly based on the actual transaction data of the New York Stock Exchange, the cash return on net assets and liquidity difference index under the market-maker and limited-order. Roger D. Huang (2002) evaluated the Nazdaq market-maker system based on the Nazdaq's transaction data and ECN bidding data from price discovery and market liquidity with the VaR model, and found that the market-maker system can produce positive synergistic effect for price discovery and liquidity of the stock market.

Domestic researches on the market-maker system and NEEQ still focus on empirical study. Feng Wei (2005) focused on the practice and analysis of market maker systems in capital markets in 
different countries and regions, and summarizes the overseas market maker system. On the basis of lessons learned and related theoretical research results, it is considered that the market maker system as an important auxiliary transaction system is of great significance to China's multi-level financial markets. Chen Jianli, Ye Dongjiang, and Zhou Minghua (2009) break down market risk into price risk and liquidity risk through the revision of the VaR model. Chen Hui and Gu Naikang (2017) evaluated the performance of NEEQ under the market-maker system in more detail through the Diff Method., and found that the market maker system did not bring about a significant improvement in the average value of trading volume and the average turnover rate, However, the median number and the number of non-zero trading days and price impact indicators have been significantly improved, which generally confirms the positive impact of the market maker system on stock liquidity and securities value.

\section{Risk Qualification of VaR Method Based on GARCH Model}

\subsection{The GARCH model}

In reality, the financial time series model generally has obvious heteroskedasticity, and its "peak and thick tail" feature and volatility agglomeration phenomenon are significant, which is not applicable to the general regression model. Therefore, Engle proposed the ARCH model in 1982, then Bollerslev further optimized the expression of the variance based on the ARCH model, and proposed the GARCH model, which is a generalized autoregressive conditional heteroskedasticity model. The GARCH model consists of the mean equation and variance equation, and its mathematical expression is equation (1) and (2).

$$
\begin{gathered}
R_{t}=\mu+\varepsilon_{t} \\
\sigma_{t}^{2}=\alpha_{0}+\alpha_{1} \varepsilon_{t-1}^{2}+\alpha_{2} \varepsilon_{t-2}^{2}+\cdots+\alpha_{p} \varepsilon_{t-p}^{2}+\beta_{1} \varepsilon_{t-1}^{2}+\beta_{2} \varepsilon_{t-2}^{2}+\cdots+\beta_{q} \varepsilon_{t-q}^{2}
\end{gathered}
$$

In equation (1) and (2), $R_{t}$ is assets income of modified mean, $\mu$ is unconditional mean, $\varepsilon_{t}$ is independent residual term, $\sigma_{t}^{2}$ is conditional variance of $\varepsilon_{t}^{2}$. In general, assume that the conditional distribution of residual term $\varepsilon_{t}^{2}$ satisfies characteristics of a standard normal distribution. However, if the conditional distribution is assumed to follow the GED distribution, it can be said that assets income series exhibits characteristics of "peak and thick tail".

\subsection{VaR model method}

VaR (Value at Risk) is usually defined as the maximum loss that may occur in a certain portfolio when confidence interval and holding period are given under normal market conditions, that is, the value at risk at a certain confidence level. The VaR values can usually be calculated through historical simulation method, the Monte Carlo simulation method, and the variance-covariance method. At the same time, due to the feature of "peak and thick tail” in return in financial market, the traditional VaR method can easily lead to underestimation of risks. Therefore, this paper uses the variance-covariance Method, and the conditional variance in the GARCH model to estimate parameters in NEEQ stock market.

The variance-covariance method refers to the product of quantiles, making use of the correspondence between the quantile and the confidence in the normal distribution under the assumption of a normal distribution, and calculating the VaR of the portfolio to be equal to the standard deviation of the portfolio return and the corresponding confidence, shown in equation (3).

$$
\operatorname{VaR}=\omega_{0} Z_{\alpha} \sigma \sqrt{\Delta t}
$$

\section{Empirical Analysis of Risk of NEEQ Market}

Taking into account the requirements of the VaR model method on the sample data volume, this paper selects the NEEQ market-maker index in a total of 778 trading days from 2015.01.05 to 2018.03.19 as the analysis sample. 
Data resource: Wind

This paper first uses Eviews8 to generate a logarithmic series of sample data, shown in equation (4).

$$
r=\log \left(\frac{\text { price }}{\text { price }(-1)}\right)
$$

In equation (4), price is the closing price on the $t_{\text {th }}$ day, and price $(-1)$ is the closing price on the $t$ $1_{\text {th }}$ day. The opponent's return series $r$ can be obtained by calculation. The logarithmic return rate chart is shown in Figure 1.

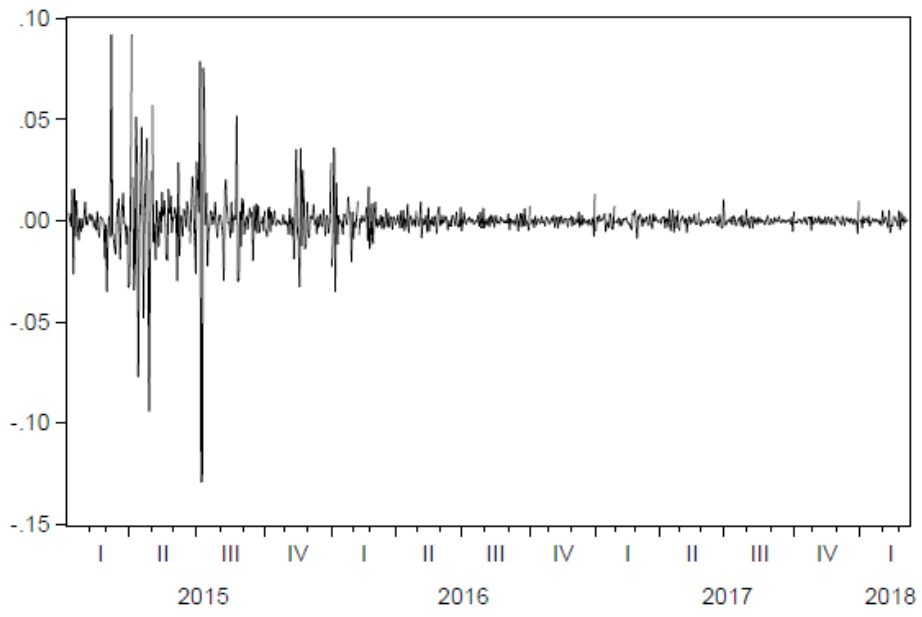

Figure 1 The logarithmic return rate

From Figure 1, it can be initially seen that there is large fluctuation characteristics in sample series, and there is more obvious volatility aggregation at the same time, which is consistent with the characteristics of the general ARCH model family, but before the GARCH model is established, characteristics of the sample series are needed for further analysis to determine whether it satisfies the conditions for establishing the GARCH model.

\subsection{Normality test}

The logarithmic return Q-Q test and descriptive statistical test can be obtained with Eviews8.0 and the test results are shown in Figure 2.

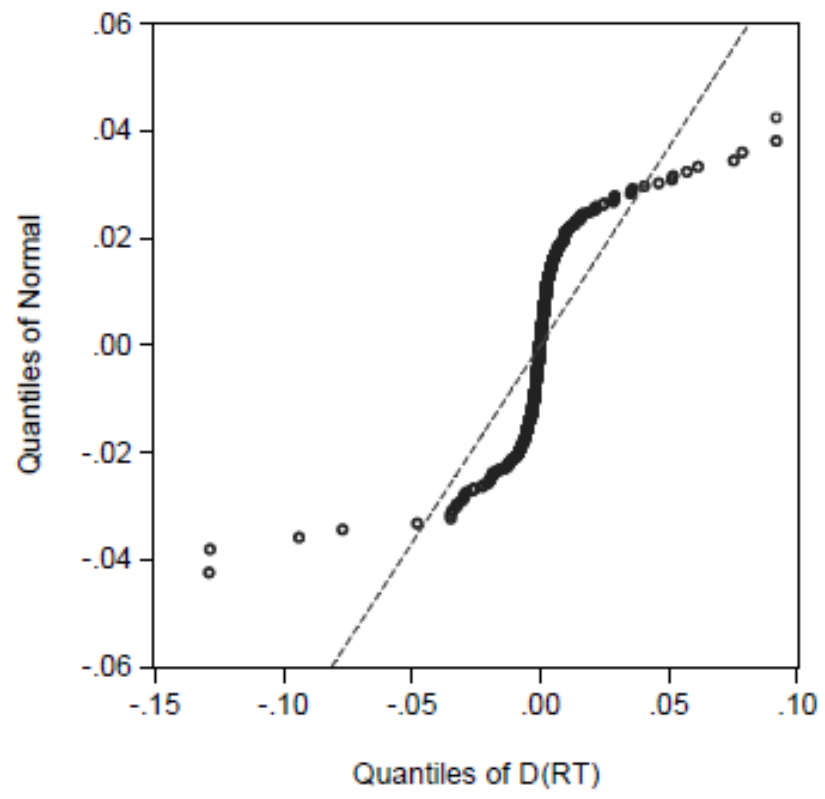

Figure $2 \mathrm{Q}-\mathrm{Q}$ test

As can be seen from Figure 2, the Q-Q test of logarithmic return rate series of the NEEQ 
market-maker index is clearly not a straight line, indicating that the rate of return does not obey the normal distribution, and has prominent characteristics of "peak and thick tail”.

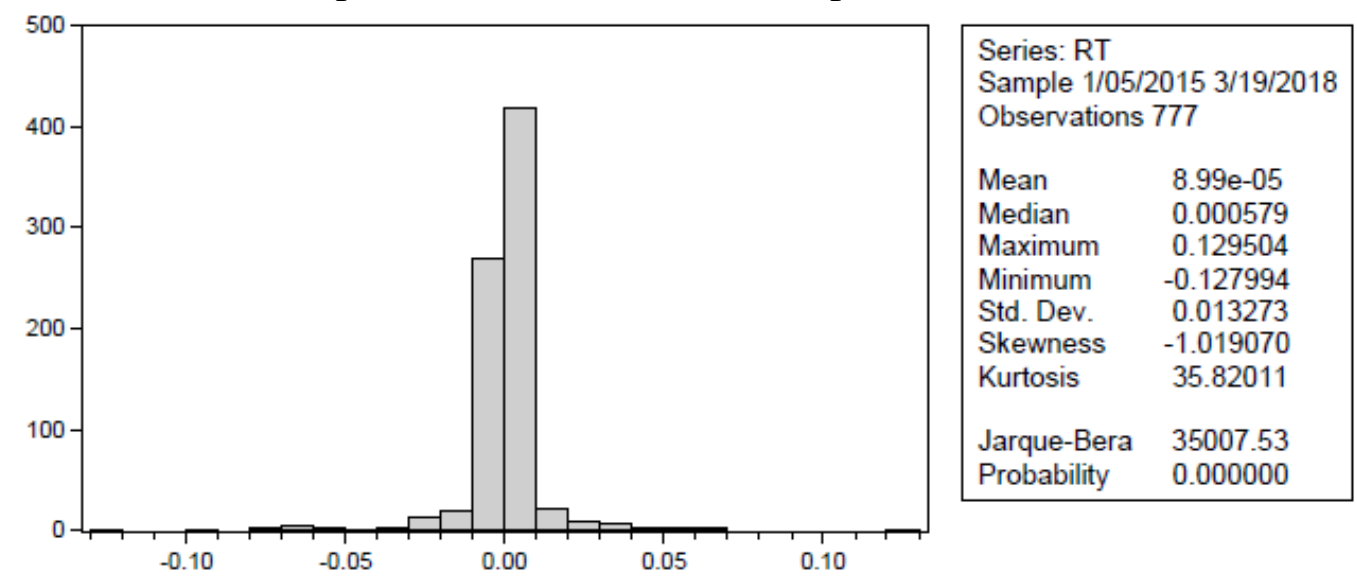

Figure 3 Descriptive statistical Test

As can be seen from Figure 3, the mean of return rate is 0.0000899 , the standard deviation is 0.013273, and the Kurtosis is 35.820110, which is far greater than the peak value of the normal distribution. Obviously, this series has significant characteristics of "peak and thick tail", the Skewness is -1.019070 , which is less than zero, and the series of return rate shifts to the right side.

\subsection{Stationary test}

In order to effectively avoid the spurious regression of the model caused by the unsteady series, this paper uses the ADF method to conduct stationary test on the daily return rate of NEEQ market-maker index. The test results are shown in Table 1.

Table 1 ADF test

\begin{tabular}{|c|c|c|c|}
\hline & & T statistics & $\mathrm{P}$ value \\
\hline \multicolumn{2}{|c|}{ ADF statistics } & -9.370 & 0.000 \\
\hline \multirow{3}{*}{ Confidence level } & $1 \%$ & -3.438 & \\
\hline & $5 \%$ & -2.865 & \\
\hline & $10 \%$ & -2.568 & \\
\hline
\end{tabular}

From test results of Table 1, it can be seen that the ADF value is -9.370472 , which is far less than the critical value -2.565916 in the case where the significance level is $1 \%$. Therefore, the original hypothesis is rejected, and the unit root is not considered in the return rate series, which is stable and there is no spurious regression.

\subsection{Autocorrelation Test}

Autocorrelation refers to the correlation between the expected values of the random error term, which is mainly caused by factors such as the characteristics of the economic variable and the choice of model function. When there is autocorrelation in model, the estimation of ordinary least squares method is still unbiased estimation, but there is no validity. Therefore, taking into account the validity of the model, this paper uses Eviews8 to perform the autocorrelation test on the logarithmic return rate of NEEQ market-maker index, and the test results are shown in Figure 4.

From Figure 4, it can be seen that the autocorrelation coefficient of overall series and partial autocorrelation coefficient of the series are close to zero and the $\mathrm{P}$ value is zero. Therefore, this paper rejects the null hypothesis that there is autocorrelation in logarithmic return rate, and believes that the time series of the return rate is smooth and there is no autocorrelation, so a general mean regression equation can be established. 


\begin{tabular}{|c|c|c|c|c|c|c|}
\hline \multicolumn{7}{|c|}{$\begin{array}{l}\text { Date: } 04 / 18 / 18 \text { Time: } 14: 53 \\
\text { Sample: } 1 / 05 / 20153 / 19 / 2018 \\
\text { Included observations: } 777\end{array}$} \\
\hline Autocorrelation & Partial Correlation & & $A C$ & PAC & Q-Stat & Prob \\
\hline 吅 & $1 上$ & 1 & 0.508 & 0.508 & 201.00 & 0.000 \\
\hline$\omega$ & $\Rightarrow$ & & 0.042 & -0.291 & 202.37 & 0.000 \\
\hline 1 & 10 & & -0.040 & 0.118 & 203.61 & 0.000 \\
\hline ip & 1] & & 0.062 & 0.066 & 206.57 & 0.000 \\
\hline ص & שי & & 0.174 & 0.123 & 230.35 & 0.000 \\
\hline ص & $\sqrt{1}$ & 6 & 0.118 & -0.053 & 241.21 & 0.000 \\
\hline$\sqrt{11}$ & ip & 7 & 0.036 & 0.044 & 242.21 & 0.000 \\
\hline 13 & in & 8 & 0.052 & 0.061 & 244.35 & 0.000 \\
\hline 白 & 19 & 9 & 0.144 & 0.110 & 260.75 & 0.000 \\
\hline 吕 & 川 & 10 & 0.146 & -0.013 & 277.61 & 0.000 \\
\hline 中 & 情 & 11 & 0.042 & -0.029 & 279.01 & 0.000 \\
\hline i & 1 & 12 & -0.019 & 0.006 & 279.30 & 0.000 \\
\hline 惝 & in & 13 & 0.012 & 0.022 & 279.42 & 0.000 \\
\hline$\sqrt{1}$ & in & 14 & 0.036 & -0.042 & 280.46 & 0.000 \\
\hline ז & , & 15 & -0.004 & -0.049 & 280.47 & 0.000 \\
\hline d & 山 & 16 & -0.042 & -0.010 & 281.88 & 0.000 \\
\hline 少 & if & 17 & 0.043 & 0.114 & 283.37 & 0.000 \\
\hline 官 & 1 & 18 & 0.147 & 0.054 & 300.63 & 0.000 \\
\hline ص局 & ص1 & 19 & 0.220 & 0.144 & 339.45 & 0.000 \\
\hline 垖 & I & 20 & 0.216 & 0.096 & 376.66 & 0.000 \\
\hline 1 & $\sqrt{1}$ & 21 & 0.117 & 0.020 & 387.59 & 0.000 \\
\hline 小 & in & 22 & 0.019 & -0.040 & 387.87 & 0.000 \\
\hline$\sqrt{1}$ & 1) & 23 & -0.022 & -0.041 & 388.26 & 0.000 \\
\hline d & d. & 24 & -0.055 & -0.102 & 390.66 & 0.000 \\
\hline$d_{1}$ & 1 & 25 & -0.058 & -0.044 & 393.39 & 0.000 \\
\hline 业 & ip & 26 & 0.020 & 0.037 & 393.73 & 0.000 \\
\hline 少 & $\sqrt{1}$ & 27 & 0.017 & -0.105 & 393.97 & 0.000 \\
\hline 1 & 小 & 28 & -0.003 & 0.005 & 393.97 & 0.000 \\
\hline 1 & 14 & 29 & -0.023 & -0.046 & 394.42 & 0.000 \\
\hline d & 11 & 30 & -0.042 & -0.016 & 395.88 & 0.000 \\
\hline 小 & $1)$ & 31 & -0.007 & 0.037 & 395.92 & 0.000 \\
\hline d & [1 & 32 & -0.043 & -0.069 & 397.40 & 0.000 \\
\hline d & 1) & 33 & -0.040 & 0.086 & 398.71 & 0.000 \\
\hline$\|_{1}$ & $\Gamma_{1}$ & 34 & -0.028 & -0.006 & 399.35 & 0.000 \\
\hline d & 中 & 35 & -0.055 & -0.039 & 401.86 & 0.000 \\
\hline $1 / 1$ & 10 & 36 & -0.010 & 0.050 & 401.93 & 0.000 \\
\hline
\end{tabular}

Figure 4 Autocorrelation test

\subsection{Heteroskedasticity Test}

Whether the ARCH effect exists in the return rate series is the key to whether or not the ARCH model can be established. Therefore, the ARCH effect is tested on logarithmic return rate series residuals of NEEQ market-maker system in this paper, and the test results are shown in Table 2.

Table 2 ARCH-LM test

\begin{tabular}{cccc}
\hline F statistics & Obs statistics & F statistics P value & P value \\
\hline 112.866 & 98.756 & 0.000 & 0.000 \\
\hline
\end{tabular}

From Table 2, it can be seen that both the F-statistics and the p-value of the Obs*R-squared statistic are close to zero, so the null hypothesis is rejected and there is the ARCH effect in residual series, which indicates that there is a strong heteroskedasticity in the logarithmic return rate of NEEQ market-maker index. To sum up, it is reasonable to establish that a GARCH model fit the return rate series.

\subsection{GARCH modeling}

GARCH modeling of sample data is conducted with Eviews 8, and the model fitting results are shown in Table 3 and Table 4.

Table 3 GARCH modeling (mean equation)

\begin{tabular}{lllll}
\hline variable & coefficient & $\begin{array}{l}\text { Standard } \\
\text { variation }\end{array}$ & Z statistics & P value \\
\hline RT1 & 0.383 & 0.030 & 12.544 & 0.000 \\
C & $3.12 \mathrm{E}-04$ & $6.15 \mathrm{E}-05$ & 5.071 & 0.000 \\
\hline
\end{tabular}


Table 4 GARCH modeling (variance equation)

\begin{tabular}{lllll}
\hline variable & coefficient & $\begin{array}{l}\text { Standard } \\
\text { variation }\end{array}$ & Z statistics & P value \\
\hline C & $6.19 \mathrm{E}-07$ & $2.32 \mathrm{E}-07$ & 2.668 & 0.007 \\
RESID(-1)^2 & 0.577 & 0.099 & 6.059 & 0.000 \\
GARCH(-1) & 0.587 & 0.033 & 17.384 & 0.000 \\
GED parameter & 0.924 & 0.040 & 23.062 & 0.000 \\
\hline
\end{tabular}

From Table 3 and Table 4, it can be seen that the ARCH and GARCH terms in the conditional variance are all significant, so the return rate series has relatively obvious volatility aggregation. After the ARCH-LM test, the main model p value is 0.8491 , which is greater than the significance level, so there is no ARCH effect.

The estimation results of GARCH model are shown in equation (5) and (6).

$$
\begin{array}{r}
\mathrm{RT}=0.383108787677 * \mathrm{RT} 1+0.000312039502931 \\
\mathrm{GARCH}=6.1931132378 \mathrm{e}-07+0.577383302429 * \mathrm{RESID}(-1)^{\wedge} 2 \\
+0.587655719028 * \mathrm{GARCH}(-1)
\end{array}
$$

\subsection{VaR calculation based on GARCH model}

In-sample prediction is applied to predict 777 trading days from 2015.01.15 to 2018.03.16 with the model established. Then the predicted conditional standard deviation is put into VaR equation, the VaR of NEEQ market-maker index at the 95\% and 99\% confidence levels respectively are obtained, and then the VaR is subtracted from the daily closing price, the risk value of $t+1_{\text {th }}$ day can be obtained, and the number of failed days in the test sample that are lower than the risk value can be calculated. The calculation result is shown in Table 5.

Table 5 VaR claculation

\begin{tabular}{cccc}
\hline Confidence level & Days tested & Days failed & Failure frequency \\
\hline $95 \%$ & 777 & 58 & $7.4 \%$ \\
$99 \%$ & 777 & 55 & $7.0 \%$ \\
\hline
\end{tabular}

From Table 5, it can be seen that calculation of the VaR method using the GARCH model can fit the value at risk of the NEEQ market-maker index more appropriately. Therefore, this paper can be used as one of the means of risk management and the construction of a corresponding risk management system.

\section{Conclusion and prospects}

According to the previous analysis and description, the VaR method based on the GARCH model can well fit the risk value of the market maker index in China's New Third Board market From the perspective of China's multi-level financial system, the risk quantitative analysis method can effectively reduce market risk and credit risk to a controllable range, in order to obtain relatively good market and social effects, and can effectively mitigate the risks brought about by the uncertainties in the construction of the NEEQ market-maker system. For financial regulation institutions, the quantitative risk control technology can effectively reduce all types of risk factors from the financial market, and accurate calculation and allocation of complex risks can also help improve China's financial supervision.

\section{References}

[1] Demsetz H. The cost of transacting [J]. The quarterly journal of economics, 1968, 82(1): 33-53.

[2] Berkman H. Large option trades, market makers, and limit orders [J]. The review of financial studies, 1996, 9(3): 977-1002.

[3] Huang R D. The quality of ECN and Nasdaq market maker quotes [J]. The Journal of Finance, 
2002, 57(3): 1285-1319.

[4] Chen Hui, Gu Naikang. The Mechanism of Market Making in the New Third Board, Stock Liquidity, and Securities Values [J]. Journal of Financial Research, 2017(04):176-190.

[5] Chen Jianli, Ye Dongjiang, Zhou Minghua. An Application of VaR in Liquidity Risk Measure [J]. Journal of Zhejiang University of Technology, 2009, 37 (05):586-590.

[6] Feng Wei. View of Overseas Market Making Experience and Research Results [J]. Securities Market Herald, 2005 (01): 65-71. 